\title{
PARTISIPASI MASYARAKAT DALAM PENGELOLAAN SAMPAH PANTAI TELUK PENYU CILACAP
}

\author{
Nandang Bekti Karnowati*, Esih Jayanti \\ Sekolah Tinggi Ilmu Ekonomi Muhammadiyah Cilacap \\ "Email: nandangbekti@stiemuhcilacap.ac.id
}

\section{ABSTRACT \\ COMMUNITY PARTICIPATION IN WASTE MANAGEMENT TELUK PENYU BEACH CILACAP}

The problem of waste is a challenge faced by most countries in the world. The problem of waste will continue if not addressed and will pollute the environment and negatively impact the tourist attraction area. For that, there needs to be real action to overcome the problem of Cilacap Turtle Bay beach waste. The purpose of this study is to find out the influence of variable understanding, will and income on community participation in waste management. Respondents are people who live on the coast of Turtle Bay as many as 100 people. The data was analyzed using Partial Least Square by measuring the outer model and the inner model. The results showed that the variables of understanding, willingness and income positively affect community participation in turtle bay waste management. Government support is the motivation that people expect in sustainable waste management.

Keywords: participation; waste management; understanding; willingness; income.

\section{PENDAHULUAN}

Industri wisata merupakan salah satu sektor yang mampu menunjukkan kinerjanya sebagai sektor industri yang prospektif dan mampu mendukung pembangunan dan perekonomian negara. Pada tahun 2018 sektor wisata menyumbang devisa USD 19,2 milyar, sehingga mampu mengalahkan sektor migas (Kuntadi, 2019). Kawasan wisata pantai Teluk Penyu merupakan objek wisata yang paling diminati di Cilacap dan merupakan objek wisata yang menyumbang Pendapatan Asli Daerah paling besar di Cilacap (Pamungkas, 2019). Menurut BPS Kabupaten Cilacap (BPS, 2020) jumlah pengunjung pantai Teluk Penyu mencapai titik puncak pada tahun 2017 yaitu sebanyak 240.666 wisatawan. Dari jumlah tersebut dapat diambil rata-rata perhari terdapat kurang lebih 600 wisatawan. Meningkatnya jumlah wisatawan seiring dengan meningkatnya aktivitas wisata yang menyebabkan meningkatnya volume sampah di kawasan wisata Teluk Penyu. Timbulan sampah setiap hari yang terus meningkat akan menyebabkan pencemaran lingkungan, rusaknya pemandangan dan kenyamanan pengunjung di kawasan wisata.

Masalah sampah yang tidak kunjung diatasi akan terus berlanjut dan berdampak negatif pada lingkungan dan objek wisata. Meningkatnya timbulan sampah merupakan tantangan dan masalah yang selalu ditemui dan harus dihadapi oleh negara-negara di dunia (Assuah \& Sinclair, 2021). Penyebab sebaran sampah dipinggir pantai karena kebiasaan masyarakat membuang sampah sembarangan walaupun terdapat tempat sampah disekitar lokasi wisata dan kebiasaan membuang sampah ke sungai sehingga sampah rumah tangga terbawa arus ke laut (Ermawati et al., 2018). Masalah sampah jelas akan berdampak pada berkurangnya nilai estetika di kawasan wisata, hal tersebut disebabkan karena rendahnya pemahaman atau pengetahuan masyarakat serta kemauan masyarakat untuk menjaga kebersihan lingkungan serta kemampuan pendapatan 
masyarakat untuk berperan dalam mengelola sampah (Yuliastuti et al., 2013). Perilaku atau sikap yang kemudian membentuk kemauan atau kesadaran terhadap lingkungan adalah faktor terpenting untuk mewujudkan lingkungan bersih (Hartono, 2020). Kontribusi masyarakat untuk berpartisipasi dalam pengelolaan sampah dipengaruhi oleh pendapatan masyarakat (Dewi, 2021); (Timang et al., 2019); (Sari \& Anggoro, 2020). Penelitian ini merujuk pada penelitian (Yuliastuti et al., 2013) dimana memiliki kesamaan variabel dengan perbedaan objek yang diteliti dan lokasi penelitian. Hasil penelitian (Yuliastuti et al., 2013) menunjukan bahwa kemauan, pendapatan dan pemahaman berdampak positif terhadap partisipasi masyarakat dalam mengelola sampah. Untuk itu peneliti merasa bahwa untuk meningkatkan partisipasi masyarakat perlu mengetahui pengaruh kemauan, pendapatan dan pemahaman masyarakat.

Tujuan penelitian untuk mengetahui pengaruh variabel kemauan, pemahaman dan pendapatan terhadap partisipasi pengelolaan sampah. Hasil temuan penelitian digunakan untuk menggali metode yang paling tepat untuk meningkatkan partisipasi masyarakat Teluk Penyu dalam pengelolaan sampah.

\section{METODOLOGI}

\subsection{Populasi dan Teknik Sampling}

Populasi yang diambil adalah warga Kelurahan Cilacap, Kecamatan Cilacap Selatan, Kabupaten Cilacap yang bermukim dikawasan wisata pantai Teluk Penyu Cilacap. Masyarakat yang berdomisili di sepanjang pesisir pantai Teluk Penyu menjadi responden penelitian.

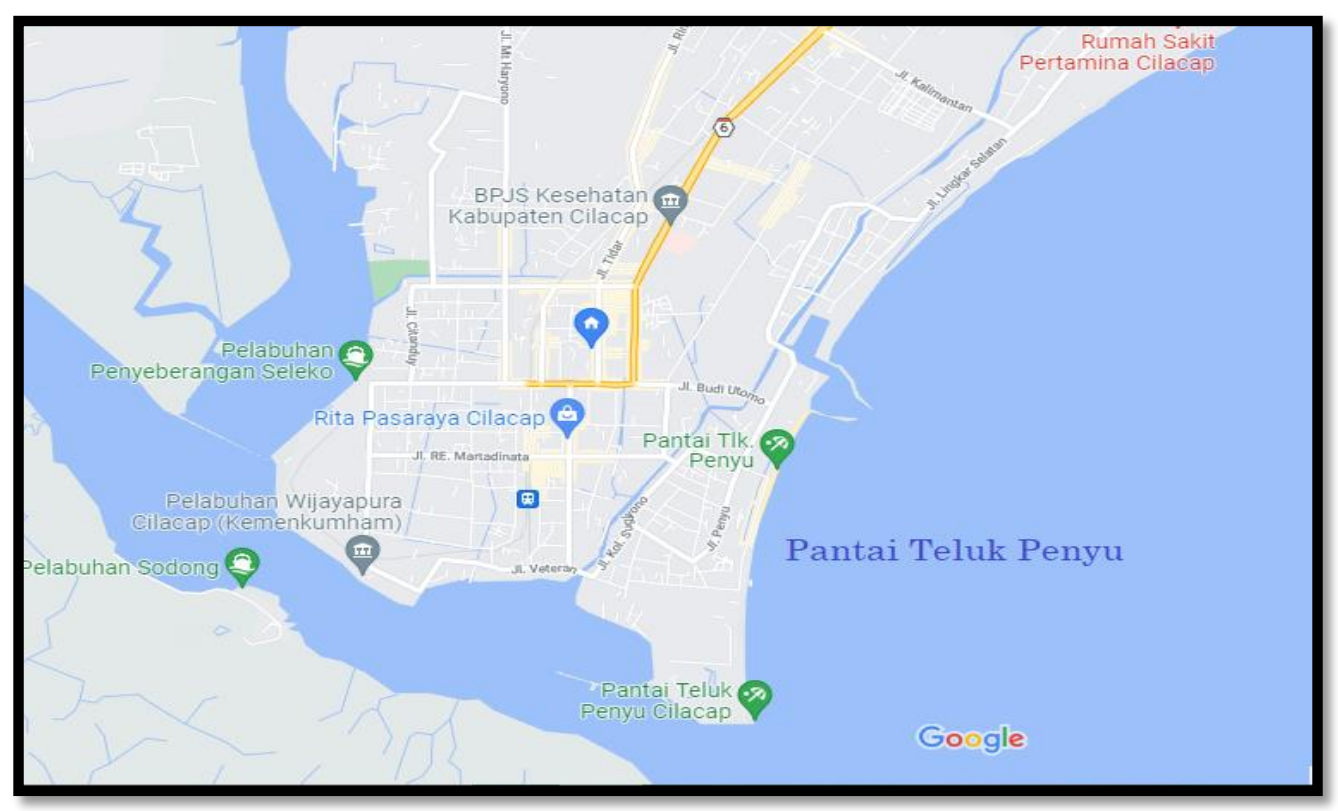

Gambar 1.

Lokasi Kegiatan Penelitian Pantai Teluk Penyu

Ukuran sampel menggunakan rumus slovin dengan batas kelonggaran ketelitian $(e)$ 0,1. Jumlah Populasi penduduk Kelurahan Cilacap sebesar 19.299 orang (BPS, 2020), dimana keterangan di dalam rumus jumlah sampel $(n)$, banyaknya populasi $(N)$, sehingga hitungan jumlah sampel adalah:

$$
n=\frac{N}{\left(1+N(e)^{2}\right)}
$$

Hitungan sampel:

$$
\begin{aligned}
& n=\frac{19.299}{\left(1+19.299(0,1)^{2}\right)} \\
& n=99,2 \\
& n=100 \text { (pembulatan) }
\end{aligned}
$$

Metode pengambilan sampel dengan simple random sampling, dimana sampel diambil secara acak dan memberikan kesempatan yang sama pada warga untuk menjadi responden tanpa memperhatikan tingkatan atau status (Sugiyono, 2012). Metode 
pengumpulan data menggunakan beberapa cara antara lain studi pustaka, observasi langsung dan wawancara langsung kepada warga dan praktisi atau pakar pengelola kawasan wisata. Penyebaran kuesioner dilakukan secara langsung kepada warga kawasan wisata.

\subsection{Variabel Penelitian}

Variabel dalam penilitian ini yaitu partisipasi masyarakat sebagai variabel dependen sedangkan pemahaman, kemauan dan pendapatan masyarakat di Teluk Penyu sebagai variabel independen.

1) Partisipasi Masyarakat

Partisipasi merupakan peran aktif masyarakat dalam kegiatan kemasyarakatan, baik dalam pengawasan, pelayanan, tanggung jawab dan bersedia memberi kontribusi untuk mencapai tujuan (Dewi, 2021). Dari definisi tersebut maka instrumen partisipasi masyarakat dapat diukur dengan indikator pada Tabel 1.

2) Pemahaman Masyarakat

Pemahaman masyarakat merupakan kesadaran masyarakat dalam bersikap peduli terhadap kebersihan lingkungan, mentaati peraturan dan melaksanakan kewajiban dalam kegiatan lingkunga. Instrumen variabel pemahaman masyarakat merujuk pada indikator pemahaman masyarakat penelitian (Yuliastuti et al., 2013) pada Tabel 2.

3) Kemauan Masyarakat

Kemauan masyarakat adalah motivasi dari dalam diri yang mendorong masyarakat melakukan aktivitas yang terarah dan tersususn agar tercapai tujuan yang diharapkan masyarakat. Indikator pemahaman masyarakat merujuk pada penelitian (Yuliastuti et al., 2013) pada Tabel 3.

4) Pendapatan Masyarakat

Kegiatan pengelolaan sampah yang meliputi pelayanan pengangkutan dan pengadaan fasilitas membutuhkan biaya operasional (Arifa et al., 2019). Biaya tersebut diperoleh dari hasil pembayaran retribusi sampah dari masyarakat yang membayar, sehingga terdapat hubungan pendapatan dengan partisipasi masyarakat. Pendapatan merupakan penerimaan seseorang dalam satu bulan yang dipakai untuk memenuhi kebutuhan (Burhanuddin et al., 2021). Instrumen pendapatan masyarakat merujuk penelitian (Yuliastuti et al., 2013) pada Tabel 4.

\subsection{Analisis Data}

Penelitian ini adalah jenis penelitian diskriptif kuantitatif dengan tujuan ada atau tidaknya dampak pemahaman masyarakat, kemauan masyarakat dan pendapatan terhadap pertisipasi masyarakat di Teluk Penyu. Analisis penelitian dengan model persamaan struktural Partial Least Square (PLS) yaitu metode dengan konstruk laten dan multiple indikator untuk memperkirakan path model (Ghozali, 2015).

Data penelitian dianalisis dengan statistik diskriptif untuk menggambarkan karakteristik responden dari jawaban responden yang meliputi usia, jenis kelamin, status, pekerjaan, pendapatan dan lama bermukim di kawasan wisata Teluk Penyu. Kuesioner dengan skala likert dimana lima alternatif jawaban yang kemudian disebarkan kepada warga kawasan wisata pantai Teluk Penyu. Untuk menguji validitas dengan ukuran keberhasilan loading factor dan Average variance Extracted (AVE) memiliki nilai >0,5. Uji reliabilitas dengan parameter nilai composite reliability $>0,6$ sebagai ukuran keberhasilan pengujian (Ghozali, 2015).

Hipotesis diuji menggunakan metode PLSSEM. Hubungan antar variabel laten diuji dengan mengukur inner model, mengevaluasi nilai $R$-square dan path coefisien. Kemudian pengujian dilanjutkan dengan uji statistik melalui boothstraping. Hasil dari olah data selanjutnya dianalisis untuk menjawab seluruh pertanyaan penelitian. 
Tabel 1. Indikator Variabel Partisipasi Masyarakat

\begin{tabular}{|c|c|c|}
\hline & Indikator & Kuesioner \\
\hline 1. & $\begin{array}{l}\text { Masyarakat terlibat dalam menyusun } \\
\text { rencana dan kegiatan kebersihan } \\
\text { kawasan wisata. }\end{array}$ & $\begin{array}{l}\text { 1. Saya terlibat aktif dalam menyusun rencana dan } \\
\text { kegiatan kebersihan dalam pengelolaan sampah di } \\
\text { kawasan wisata Teluk Penyu. }\end{array}$ \\
\hline 2. & $\begin{array}{l}\text { Lingkungan bersih adalah tanggung } \\
\text { jawab masyarakat. }\end{array}$ & $\begin{array}{l}\text { 2. Saya bertanggung jawab untuk menjaga lingkungan } \\
\text { pantai selalu bersih. }\end{array}$ \\
\hline 3. & $\begin{array}{l}\text { Masyarakat bersedia untuk mengawasi } \\
\text { kegiatan di kawasan wisata. }\end{array}$ & $\begin{array}{l}\text { 3. Saya ikut mengawasi segala kegiatan di kawasan } \\
\text { wisata Teluk Penyu. }\end{array}$ \\
\hline 4. & $\begin{array}{l}\text { Kebersihan lingkungan adalah untuk } \\
\text { meningkatkan kualitas kesehatan dan } \\
\text { kesejahteraan masyarakat. }\end{array}$ & $\begin{array}{l}\text { 4. Saya berkontribusi dalam kegiatan pengelolaan } \\
\text { sampah agar lingkungan bersih dan sehat. }\end{array}$ \\
\hline
\end{tabular}

Tabel 2. Indikator Variabel Pemahaman Masyarakat

\begin{tabular}{|c|c|c|}
\hline & Indikator & Kuesioner \\
\hline 1. & $\begin{array}{l}\text { Memberikan pemaham akan pentingnya } \\
\text { kebersihan kepada masyarakat sejak usia } \\
\text { dini agar termotivasi danmemiliki } \\
\text { kesadaran tinggi. }\end{array}$ & $\begin{array}{l}\text { 1. Saya memiliki motivasi untuk ikut menjaga } \\
\text { kebersihan pantai karena telah diberi pemahaman } \\
\text { pentingnya menjaga kebersihan sejak dini. }\end{array}$ \\
\hline 2. & $\begin{array}{l}\text { Masyarakat menyediakan fasilitas } \\
\text { kebersihan untuk membantu kelancaran } \\
\text { program kebersihan kawasan wisata. }\end{array}$ & $\begin{array}{l}\text { 2. Saya menyediakan tempat sampah agar petugas } \\
\text { dapat terbantu dan kebersihan lingkungan kawasan } \\
\text { wisata dapat tercipta. }\end{array}$ \\
\hline 3. & $\begin{array}{l}\text { Kesehatan masyarakat akan terjamin } \\
\text { apabila masyarakat memiliki pemahaman } \\
\text { untuk mengelola sampah dengan benar. }\end{array}$ & $\begin{array}{l}\text { 3. Saya sadar dan memahami bahwa pengelolaan } \\
\text { sampah yang benar dapat menjamin kesehatan } \\
\text { masyarakat di kawasan wisata. }\end{array}$ \\
\hline 4. & $\begin{array}{l}\text { Kebersihan lingkungan dapat terwujud } \\
\text { apabila masyarakat memiliki sikap patuh } \\
\text { dan taat terhadap tata tertib dan aturan } \\
\text { yang telah disepakati. }\end{array}$ & $\begin{array}{l}\text { 4. Saya mematuhi tata tertib dan seluruh aturan yang } \\
\text { telah disepakati bersama agar kebersihan } \\
\text { lingkungan kawasan wisata dapat terwujud. }\end{array}$ \\
\hline
\end{tabular}

Tabel 3. Indikator Variabel Kemauan Masyarakat

\begin{tabular}{|c|c|c|}
\hline \multicolumn{2}{|r|}{ Indikator } & $\begin{array}{l}\text { Kuesioner } \\
\end{array}$ \\
\hline 1. & $\begin{array}{l}\text { Motivasi masyarakat dalam pengelolaan } \\
\text { sampah didukung oleh pemerintah } \\
\text { daerah setempat. }\end{array}$ & $\begin{array}{l}\text { 1. Saya memiliki kemauan untuk ikut dalam } \\
\text { pengelolaan sampah karena dukungan dari } \\
\text { pemerintah setempat. }\end{array}$ \\
\hline 2. & $\begin{array}{l}\text { Permasalahan sampah yang dihadapi } \\
\text { masyarakat ditanggapi dengan cepat oleh } \\
\text { petugas. }\end{array}$ & $\begin{array}{l}\text { 2. Saya mengharap permasalahan sampah kawasan } \\
\text { wisata mendapat respon cepat dari petugas maupun } \\
\text { dinas terkait. }\end{array}$ \\
\hline 3. & $\begin{array}{l}\text { Kebersihan lingkungan karena adanya } \\
\text { kesigapan masyarakat dan petugas } \\
\text { kebersihan kawasan. }\end{array}$ & $\begin{array}{l}\text { 3. Saya merasa bahwa lingkungan bersih di kawasan } \\
\text { wisata karena kesigapan petugas dan masyarakat. }\end{array}$ \\
\hline 4. & $\begin{array}{l}\text { Masyarakat mau membayar retribusi } \\
\text { sampah sesuai dengan ketetapan untuk } \\
\text { mendukung program pemerintah. }\end{array}$ & $\begin{array}{l}\text { 4. Saya tertib membayar retribusi sampah sesuai } \\
\text { dengan ketentuan untuk mendukung program } \\
\text { pemerintah. }\end{array}$ \\
\hline
\end{tabular}

Tabel 4. Indikator Variabel Pendapatan Masyarakat

\begin{tabular}{|c|c|c|}
\hline \multicolumn{2}{|r|}{ Indikator } & Kuesioner \\
\hline 1. & $\begin{array}{l}\text { Masyarakat membayar retribusi sampah } \\
\text { sesuai dengan peraturan pemerintah. }\end{array}$ & $\begin{array}{l}\text { 1. Saya membayar retribusi sampah sesuai dengan } \\
\text { aturan yang ditetapkan pemerintah. }\end{array}$ \\
\hline 2. & $\begin{array}{l}\text { Pengelolaan sampah ditunjang oleh } \\
\text { besarnya retribusi yang dibayarkan } \\
\text { masyarakat. }\end{array}$ & $\begin{array}{l}\text { 2. Biaya retribusi yang telah saya bayar adalah untuk } \\
\text { memnunjang kegiatan pengelolaan sampah } \\
\text { kawasan wisata Teluk Penyu. }\end{array}$ \\
\hline 3. & $\begin{array}{l}\text { Pembayaran retribusi sampah yang tertib } \\
\text { dan disiplin meningkatkan pelayanan } \\
\text { petugas sampah. }\end{array}$ & $\begin{array}{l}\text { 3. Jika saya membayar biaya pungutan retribusi } \\
\text { sampah dengan disiplin maka pelayanan dan } \\
\text { fasilitas kebersihan kawasan wisata meningkat. }\end{array}$ \\
\hline 4. & $\begin{array}{l}\text { Meningkatnya pendapatan dapat } \\
\text { meningkatkan pungutan biaya retribusi } \\
\text { sampah. }\end{array}$ & $\begin{array}{l}\text { Jika pendapatan saya meningkat maka saya } \\
\text { bersedia untuk menambah biaya pungutan retribusi } \\
\text { sampah. }\end{array}$ \\
\hline
\end{tabular}




\section{HASIL DAN PEMBAHASAN}

\subsection{Outer Model}

Hasil uji validitas dengan outer model ditunjukan pada loading factor, dimana loading factor harus memiliki nilai diatas 0,6. Tabel 5 menunjukan seluruh indikator loading factor memiliki nilai korelasi > 0.6 yang berarti bahwa konstruk memiliki nilai convergent validity baik.

Tabel 5. Variabel, Indicators, Loading Factor, AVEs dan Composite Reliability

\begin{tabular}{|c|c|c|c|c|}
\hline Variables & Indicators & Loading Factors ${ }^{\mathrm{a}}$ & $\mathrm{AVEs}^{\mathrm{b}}$ & Composite Reliability $^{\mathrm{c}}$ \\
\hline \multirow[t]{4}{*}{ Pemahaman Masyarakat } & PEMM1 & 0.786 & \multirow[t]{4}{*}{0.688} & \\
\hline & PEMM2 & 0.764 & & 0.898 \\
\hline & PEMM3 & 0.906 & & \\
\hline & PEMM4 & 0.854 & & \\
\hline \multirow[t]{4}{*}{ Kemauan Masyarakat } & KEMM1 & 0.880 & \multirow[t]{4}{*}{0.667} & \\
\hline & KEMM2 & 0.821 & & 0.889 \\
\hline & KEMM3 & 0.809 & & \\
\hline & KEMM4 & 0.753 & & \\
\hline \multirow[t]{4}{*}{ Pendapatan Masyarakat } & PENM1 & 0.840 & \multirow[t]{4}{*}{0.723} & \\
\hline & PENM2 & 0.909 & & 0.912 \\
\hline & PENM3 & 0.932 & & \\
\hline & PENM4 & 0.712 & & \\
\hline \multirow[t]{4}{*}{ Partisipasi Masyarakat } & PARM1 & 0.873 & \multirow[t]{4}{*}{0.786} & \\
\hline & PARM2 & 0.903 & & 0.906 \\
\hline & PARM3 & 0.752 & & \\
\hline & PARM4 & 0.830 & & \\
\hline
\end{tabular}

Sumber: data diolah dari hasil kuesioner

\subsection{Inner Model}

Pengujian inner model pada nilai $R$ square menunjukan prediksi hubungan antar variabel laten. Gambar 1 menunjukan bahwa nilai $R$-square pertisipasi masyarakat adalah 0,793 yang diinterpretasikan bahwa variabel partisipasi masyarakat dapat dijelaskan oleh variabel pemahaman, kemauan dan pendapatan masyarakat sebesar $79,3 \%$.

Hasil uji statistik melalui boothstraping disajikan pada Tabel 6 yang menunjukan hasil seluruh variabel memiliki nilai Pvalue < 0,05 sehingga seluruh hipotesis $(\mathrm{H} 1, \mathrm{H} 2$ dan H3) diterima.

Tabel 6. Variabel, Indicators, Loading Factor, AVEs dan Composite Reliability

\begin{tabular}{llll}
\hline Relationships & $\begin{array}{l}\text { Original } \\
\text { Sample }\end{array}$ & P values & Results \\
\hline Pemahaman Masyarakat $\rightarrow$ Partisipasi Masyarakat (H1) & 0.156 & 0.021 & Diterima \\
Kemauan Masyarakat $\rightarrow$ Partisipasi Masayrakat (H2) & 0.398 & 0.002 & Diterima \\
Pendapatan Masyarakat $\rightarrow$ Partisipasi Masayrakat (H3) & 0.455 & 0.000 & Diterima \\
\hline
\end{tabular}

Sumber: data diolah dari hasil kuesioner 


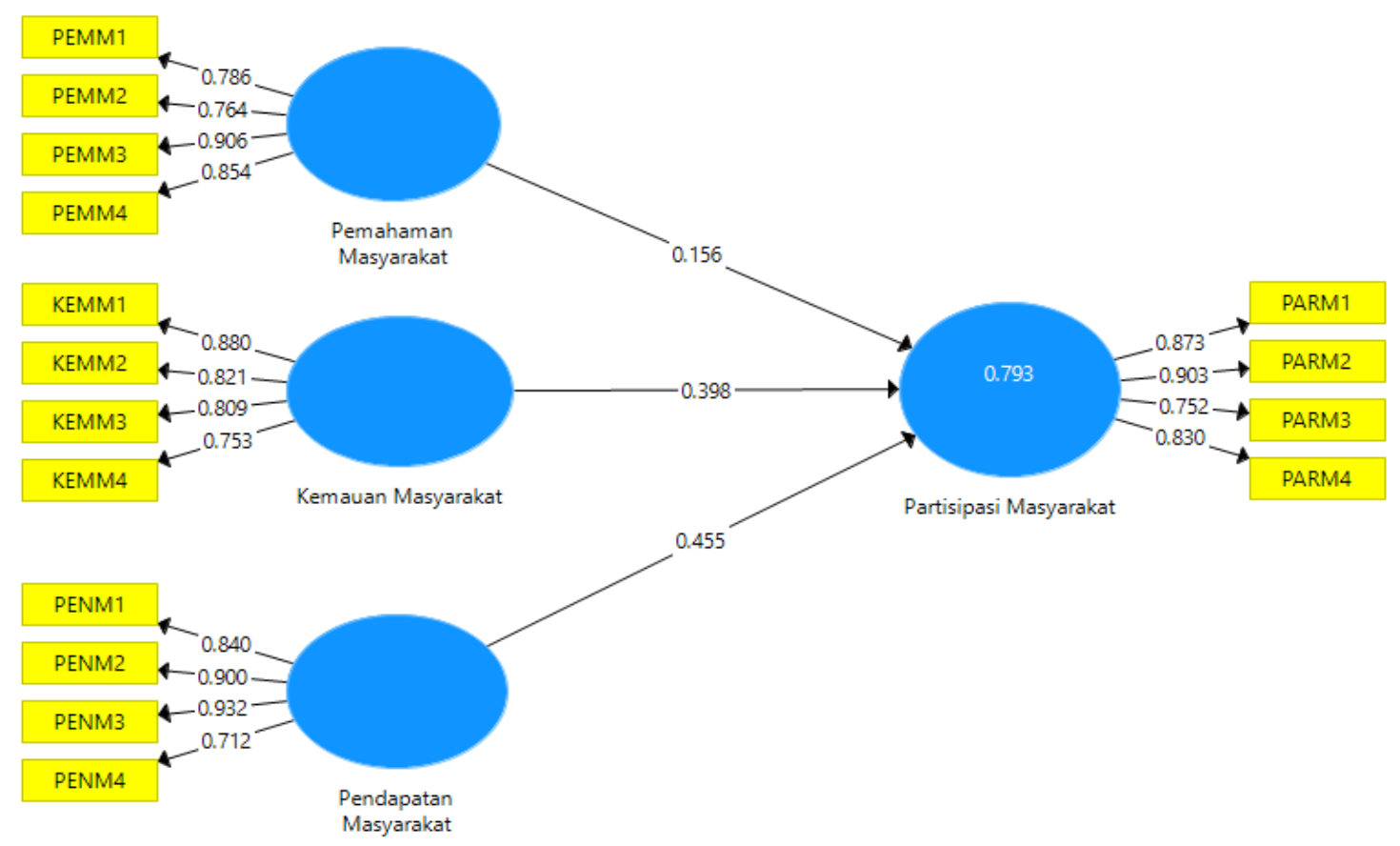

Gambar 2.

Model Persamaam Struktural

\subsection{Pembahasan}

1) Pengaruh pemahaman masyarakat terhadap partisipasi masyarakat

Penelitian ini memiliki hasil yang konsisten dengan penelitian (Yuliastuti et al., 2013); (Dompak \& Simarmata, 2014);(Diniaty et al., 2019) yang manyatakan bahwa pemahaman berpengaruh positif terhadap partisipasi masyarakat. Pemahaman adalah kemampuan untuk menerangkan, menjelaskan, memberi contoh dan menyimpulkan sesuai dengan pengetahuan yang dimiliki masyarakat (Suharsimi, 2009).

Tingkat pemahaman masyarakat yang semakin baik akan berdampak positif terhadap tingkat partisipasi masyarakat dalam mengelola sampah .Untuk itu diharapkan adanya dukungan pemerintah maupun swasta untuk meningkatkan pemahaman masyarakat dengan sosialisi dan pendampingan pemberdayaan masyarakat dalam mengelola sampah. Masyarakat dengan pemahaman yang tinggi akan dengan sukarela berpartisipasi dan berkontribusi dalam pengelolaan sampah sehingga terwujud kawasan wisata yang bersih dan nyaman.

2) Pengaruh kemauan masyarakat terhadap partisipasi masyarakat

Hasil penelitian menunjukan bahwa kemauan masyarakat berpengaruh positif terhadap partisipasi masyarakat. Penelitian menunjukan hasil sesuai dengan (Hartono, 2020);(Ankesa et al., 2016); (Yuliastuti et al., 2013) yang menunjukan bahwa kemauan berdampak positif terhadap partisipasi masyarakat. Kemauan merupakan kesadaran setiap individu masyarakat yang berasal dari perasaan, inisiatif dan pertimbangan yang menyebabkan timbulnya aktivitas dengan tujuan memenuhi kebutuhan (Ahmadi, 1982).

Kemauan warga yang tinggi akan meningkatkan partisipasi. Kemauan adalah harapan dan keinginan yang diwujudkan dengan sebuah tindakan. Kawasan wisata yang bersih dan nyaman adalah harapan seluruh warga masyarakat yang bermukim disekitar pantai dan merupakan tanggung jawab pengelola kawasan wisata. Masyarakat kawasan wisata Teluk Penyu sangat mengharapkan dukungan pemda setempat antara lain dengan memberikan pelayanan 
fasilitas kebersihan seperti tong sampah yang lebih banyak, tempat pembuangan sampah yang memadai, jadwal pengangkutan sampah yang lebih tertib dan petugas kebersihan yang lebih disiplin.

3) Pengaruh pendapatan masyarakat terhadap partisipasi masyarakat

Penelitian ini menunjukan hasil yang sesuai dengan penelitian (Daud, 2009); (Yuliastuti et al., 2013) yang menyatakan bahwa pendapatan masyarakat berdampak positif terhadap partsipasi masyarakat. Besarnya pendapatan masyarakat memberi peluang semakin tingginya partisipasi masyarakat. Masyarakat akan memberikan kontribusi sesuai dengan kemampuannya apabila tujuan yang akan dicapai sesuai harapan, keinginan masyarakat (Slamet, 2014).

Untuk itu diperlukan dukungan pemerintah dan pihak swasta untuk mengupayakan program peningkatan kesejahteraan masyarakat pesisir pantai Teluk Penyu. Menurut Sari (2013) program pemberdayaan masyarakat dalam mengelola sampah pantai dengan teknologi tepat guna dapat meningkatkan kesejahteraan dan berdampak positif pada perekonomian kawasan tersebut. Sampah plastik dapat diolah menjadi industri kreatif dengan nilai jual lebih tinggi, sehingga apabila sampah dikelola dengan baik dengan penanganan yang komprehensif dan berkelanjutan dapat menambah pendapatan warga sekitar dan menggerakan ekonomi lokal.

\section{SIMPULAN DAN SARAN}

\subsection{Simpulan}

Permasalahan sampah di kawasan wisata tidak boleh diabaikan. Pengelolaan sampah yang berkelanjutan perlu diterapkan di kawasan wisata pantai Teluk Penyu Cilacap. Upaya meningkatkan pemahaman dan kemauan masyarakat untuk berpartisipasi dalam pengelolaan sampah pantai dapat dilakukan dengan sosialisasi dan pendampingan kegiatan pengelolaan sampah yang terprogram dan terkoordinir. Peningkatan pendapatan masyarakat di kawasan wisata dapat dilakukan dengan membentuk unit teknis pengelolaan sampah berbasis masyarakat dengan mengembangkan kreativitas dan ketrampilan untuk menciptakan industri kreatif berbahan dasar sampah plastik.

\subsection{Saran}

Pemerintah dan pihak terkait harus berperan aktif melakukan sosialisasi terkait program pemilahan sampah atau bank sampah. Pemda terkait hendaknya dapat meningkatkan sarana dan prasarana kebersihan serta fasilitas dan pelayanan yang memadai di kawasan wisata pantai Teluk Penyu untuk menunjang terciptanya kawasan wisata pantai yang bersih dan nyaman. Masyarakat hendaknya dapat bersinergi dengan pemerintah dan pihak terkait sehingga termotivasi untuk melaksanakan program pengelolaan sampah yang berkelanjutan.

\section{UCAPAN TERIMAKASIH}

Terimakasih kepada Direktorat Riset dan Pengabdian kepada Masyarakat Kemenristekdikti (DRPM) melaui Lembaga Penelitian dan Pengabdian kepada Masyarakat (LPPM) Sekolah Tinggi Ilmu Ekonomi Muhammadiyah Cilacap yang telah mendanai penelitian ini serta masyarakat pantai Teluk Penyu Cilacap dan tim peneliti.

\section{DAFTAR PUSTAKA}

Ahmadi, A. (1982). Psikologi Umum. PT Bina Ilmu.

Ankesa, H. A., Amanah, S., \& Asngari, P. S. (2016). Partisipasi Kelompok Perempuan Peduli Lingkungan dalam Penanganan Sampah di Sub DAS Cikapundung Jawa Barat. Jurnal Penyuluhan, 12(2), 105. https://doi.org/10.25015/penyuluhan .v12i2.10929

Assuah, A., \& Sinclair, A. J. (2021). Solid waste management in western Canadian First Nations. Waste Management, 129, 54-61. https://doi.org/10.1016/j.wasman.20 
Partisipasi Masyarakat Dalam Pengelolaan Sampah...

21.05.007

BPS. (2020). Kecamatan cilacap selatan dalam angka 2020. BPS Cilacap. https://doi.org/katalog bps 1102001.3301710

Burhanuddin, Pathiassana, M., \& Pathiussina, R. (2021). Partisipasi Masyarakat Dalam Berkelanjutan Pengelolaan Bank Sampah Di Desa Semamung. Jurnal Tambora, 5(2), 87-96.

Daud, F. (2009). Partisipasi Masyarakat Dalam Pengelolaan Lingkungan di Pemukiman Sekitar Muara Sungai Tallo Kota Makassar The Society Participant in Environment Management in Residence around Estuary of Tallo River of Makassar City. Chemica, 10(3), 9-18.

Dewi, N. (2021). Kajian Partisipasi Masyarakat Dusun Bone Puteh Dalam Pengelolaan Sampah. Sosintek, 1(Mei 2021), 32-40.

Diniaty, D., Permata, E., \& Alpian, I. (2019). Pengaruh Pengetahuan, Sikap, dan Tindakan Masyarakat Terhadap Keberadaan Rumah Kelola Sampah Menggunakan Metode SEM. Jurnal Teknik Industri:, 5(1), 1. https://doi.org/10.24014/jti.v5i1.612 0

Dompak, T., \& Simarmata, N. (2014). PENGARUH PENGETAHUAN DAN SIKAP TERHADAP PARTISIPASI MASYARAKAT PADA PENGELOLAAN BANK SAMPAH DI KECAMATAN BATU AJI - KOTA BATAM. Jurnal Dialektika Publik, 44-57.

Ermawati, E. A., Amalia, F. R., \& Mukti, M. (2018). Analisis Strategi Pengelolaan Sampah di Tiga Lokasi Wisata Kabupaten Banyuwangi. Journal of Tourism and Creativity, 2(1), 25. https://jurnal.unej.ac.id/index.php/to urismjournal/article/view/13838

Fitri Arifa, Fitriah Permata Cita, \& Abdul

\section{[Nandang Bekti Karnowati, dkk]}

Hadi Ilman. (2019). Partisipasi Masyarakat Dalam Program Bank Sampah Di Kabupaten Sumbawa. Nusantara Journal of Economics, 1(01), 14-27. https://doi.org/10.37673/nje.v1i01.3 21

Ghozali, I. (2015). Structural Equation Modeling (4th ed.). BP UNDIP.

Hartono. (2020). Pemberdayaan Masyarakat Dalam Pengelolaan Sampag Di

Desa Mangunjayan Kecamatan Ponorogo. Jurnal Ilmu Administrasi Publik, 9(1), 51-55.

Kuntadi. (2019). Kalahkan Migas, Pariwisata Sumbang Devisa Terbesar USD19,2 Miliar. Okefinance.

https://economy.okezone.com/read/ 2019/08/22/320/2095457

Pamungkas. (2019). Persoalan Sampah Teluk Penyu Belum Usai. Radar Banyumas.

https://radarbanyumas.co.id

Sari, A. (2013). Kebijakan Pengelolaan Sampah Sebagai Sumber Energi Alternatif dalam Kerangka Ketahanan Daerah. Pascasarjana Universitas Indonesia. Pascasarjana Universitas Indonesia.

Sari, C., \& Anggoro, S. (2020). Edukasi Dampak Pengelolaan Sampah Sebagai Upaya Peningkatan Pemahaman Siswa Tentang Gerakan Masyarakat Hidup Sehat. Jurnal Peduli Masyarakat, 2(2), 59-64.

Slamet, Y. (2014). Pembangunan Masyarakat Berwawasan Partisipasi. Sebelas Maret University Press.

Sugiyono. (2012). Metode Penelitian Kuantitatif, Kualitatif dan R \& D.Bandung:Alfabeta. Metode Penelitian Kuantitatif, Kualitatif Dan $R$ \& D.Bandung:Alfabeta. https://doi.org/10.1017/CBO978110 7415324.004

Suharsimi. (2009). Dasar - Dasar Evaluasi 
Pendidikan (edisi revisi) (Cetakan XI). Bumi Aksara.

Timang, G. D., Tjoli, I., \& Wambrauw, L. T. (2019). Persepsi masyarakat terhadap pengelolaan sampah dan kesediaan membayar (willingness to pay) dalam pelayanan pengelolaan sampah di Distrik Manokwari Barat. Cassowary, 2(1), 01-17. https://doi.org/10.30862/casssowary .cs.v2.i1.18

Yuliastuti, I., Yasa, M., \& Jember, M. (2013). Partisipasi Masyarakat Dalam Pengelolaan Sampah Di Kabupaten Badung. E- Ekonomi Bisnis Universitas Udayana, 02, 374-393.

http://ojs.unud.ac.id/index.php/EEB/ article/view/5380 